\title{
Adsorptive Removal of Trace Concentration of Fluoride Using Orange Waste Treated Using Concentrated Sulfuric Acid
}

\author{
Hari Paudyal $^{1,2}$, Bimala Pangeni ${ }^{1}$, Katsutoshi Inoue ${ }^{1}$, Hiroyuki Harada ${ }^{3,}{ }^{*}$, Hidetaka Kawakita ${ }^{1}$, \\ Keisuke Ohto ${ }^{1}$, Shafiq Alam ${ }^{2,4}$ \\ ${ }^{1}$ Department of Applied Chemistry, Saga University, Saga, Japan \\ ${ }^{2}$ Department of Science, Memorial University, St. John's, NL, Canada \\ ${ }^{3}$ Department of Environmental Sciences, Prefectural University of Hiroshima, Hiroshima, Japan \\ ${ }^{4}$ Department of Chemical and Biological Engineering, College of Engineering, University of Saskatchewan, Saskatoon, SK, Canada
}

\section{Email address:}

harig@yahoo.com (H. Paudyal), bimelapangeni@yahoo.co.in (B. Pangeni), kanako1921@gmail.com (K. Inoue), ho-harada@pu-hiroshima.ac.jp (H. Harada),kawakita@cc.saga-u.ac.jp (H. Kawakita), ohtok@cc.saga-u.ac.jp (K. Ohto)

${ }^{*}$ Corresponding author

\section{To cite this article:}

Hari Paudyal, Bimala Pangeni, Katsutoshi Inoue, Hiroyuki Harada, Hidetaka Kawakita, Keisuke Ohto, Shafiq Alam. Adsorptive Removal of Trace Concentration of Fluoride Using Orange Waste Treated Using Concentrated Sulfuric Acid. International Journal of Materials Science and Applications. Vol. 6, No. 4, 2017, pp. 212-222. doi: 10.11648/j.ijmsa.20170604.18

Received: June 7, 2017; Accepted: June 21, 2017; Published: July 24, 2017

\begin{abstract}
Novel adsorption gel was prepared from orange juice residue by using boiling concentrated sulfuric acid to create a condensation cross-linking reaction. It was then loaded with $\mathrm{Zr}(\mathrm{IV})$ ion to create adsorption sites for fluoride ions. This prepared gel was characterized by IR, EDX, XRD, SEM and chemical analysis. Fluoride adsorption was strongly $\mathrm{pH}$ dependent and maximum adsorption occurred at $\mathrm{pH} 3-4$. The maximum adsorption capacity was drastically improved by loading $\mathrm{Zr}(\mathrm{IV})$ from $0.21 \mathrm{mmol} / \mathrm{g}$ up to $0.71 \mathrm{mmol} / \mathrm{g}$ at $303 \mathrm{~K}$. The thermodynamic parameters evaluated from adsorption isotherms at varying temperature suggested that adsorption of fluoride onto the present adsorbent is spontaneous and endothermic in nature. The adsorbed fluoride was successfully desorbed using dilute alkaline solution. Trace concentrations of fluoride contained in the actual waste plating solution was completely removed by adding small amounts of this adsorbent.
\end{abstract}

Keywords: Fluoride Removal, Adsorption, Orange Juice Residue, Sulfuric Acid Treatment, Zr(IV) Loading

\section{Introduction}

Fluoride is widespread in the environment: water, air, vegetation and in the Earth's crust which can enter ground water by natural processes [1]. An appropriate concentration of fluoride in drinking water is required for preventing dental damage but long term ingestion of water that contains excess amount of fluoride causes disease such as skeletal and teeth damage, paralysis of volition, cancer etc. [2, 3]. Fluoride containing waste water is generated in various industries including mines, semiconductor factories, pharmaceutical companies, beryllium extraction plants, fertilizer manufacturing and aluminum smelters [4-6]. Hence, contamination of ground water by fluoride is unavoidable. The most common approach for fluoride removal is by means of lime precipitation, where lime is added in order to convert fluoride ion into water insoluble precipitates of calcium fluoride, $\mathrm{CaF}_{2}$. However, the lowest fluoride concentration which can be theoretically achieved by this method is 5 $\mathrm{mg} / \mathrm{dm}^{3}$ based on the solubility of calcium fluoride, and the lowest fluoride concentration practically achieved is usually in the range of $10-20 \mathrm{mg} / \mathrm{dm}^{3}$ [7], which requires further treatment to meet the maximum acceptable contaminant level of fluoride $\left(<0.8 \mathrm{mg} / \mathrm{dm}^{3}\right)$ discharged into the environment in Japan $[6,8]$. Thus, lime precipitation method is usually coupled with further treatment such as an aluminum 
co-precipitation method to remove the remaining trace concentrations of fluoride [9]. In this method, aluminum sulfate or aluminum chloride is added and $\mathrm{pH}$ is adjusted to form precipitates of aluminum hydroxide, onto which trace concentrations of fluoride is adsorbed and co-precipitated. Although this method can successfully lower the fluoride concentration down to the WHO $\left(1.5 \mathrm{mg} / \mathrm{dm}^{3}\right)$ and Japanese environmental standards $\left(0.8 \mathrm{mg} / \mathrm{dm}^{3}\right)$ [10], it suffers from various disadvantages such as the generation of huge amounts of sludge containing huge amounts of water which requires further treatment [9]. Donnan dialysis [10, 11] and membrane process [12] are also effective techniques for the removal of trace amounts of fluoride from water. However, since these methods are expensive for waste water treatment, their commercialization has not been achieved. Consequently, there is an urgent need to develop more efficient and low cost technology to remove such trace concentrations of fluoride.

In recent years, much attention has been attracted to adsorption technology using natural polymers or biomass wastes, biosorption, as an economical and environmentally benign technology $[13,14]$. Adsorptive removal of fluoride effectively making use of natural polymers contained in various biomass wastes can be also expected as alternative to the above-mentioned techniques.

Huge volumes of juice are produced from oranges in many countries and areas including Japan. In orange juice factories in Japan, oranges, after harvesting, are mechanically peeled and pressed for juicing [15], where one half of orange by weight is converted into orange juice while another one half is remained as orange juice residue, which is abbreviated as OJR (Orange Juice Residue) hereafter. Majority of OJR has not been effectively used except for additives of cattle foods in Japan. In our previous work [16], gold (III) can be effectively and selectively adsorbed from acidic

chloride media on the gel prepared from OJR by treating in boiling concentrated sulfuric acid, which is abbreviated as ATOJR (Acid Treated Orange Juice Residue) hereafter, where the maximum amount of gold adsorption was as high as around $2 \mathrm{~kg} / \mathrm{kg}$-dry adsorbent, i.e. twice the amount of the dry adsorbent itself.

ATOJR principally consists of polysaccharides such as cellulose, hemicellulose and pectin as well as chlorophyll pigment and other low molecular weight compounds like limonene and so on. Pectin contains carboxyl groups as well as its methyl ester groups, which can be easily converted into carboxyl groups by saponification reaction using alkaline materials such as lime water. In order to effectively use OJR as adsorbents for cationic metal ions, such methyl ester portion should be converted into carboxyl groups which exhibit high affinity for cationic metal ions. In our other previous work [17], we studied the adsorptive removal of some heavy metals such as lead (II) using OJR treated by the saponification reaction using calcium hydroxide, which is abbreviated as SOJR (Saponified Orange Juice Residue) hereafter. Furthermore, we also studied the adsorptive removal of trace concentrations of fluoride using SOJR loaded with high valent metal ions such as aluminum (III), tin (IV), lanthanum (III), titanium (IV) and zirconium (IV) [18, 19]. Although the metal loaded SOJR was able to successfully remove trace concentrations of fluoride, it suffered from a problem of high production cost because large volume of washing water was required to remove residual calcium and water soluble organics. In order to resolve this problem, we also prepared another type of adsorption gel using dried orange juice residue which is marketed as additive of cattle food [20]. This type of gel is abbreviated as DOJR (Dried Orange Juice Residue) hereafter. In these works, it was demonstrated that high valent metal ions, zirconium (IV) in particular, loaded onto SOJR or DOJR exhibit high selectivity to fluoride ion over other anionic species such as sulfate and chloride. However, both SOJR and DOJR gels suffered from another problem of decaying which generates odor during long time use, impeding its practical use. In the present work, in order to resolve the above-mentioned problems and extend the field of effective use of OJR, we investigated the feasibility of ATOJR to be employed as the adsorption gel for removing trace concentrations of fluoride from aquatic environments. In this case, we selected $\mathrm{Zr}(\mathrm{IV})$ ion as the loaded metal ion onto ATOJR because it exhibited highest adsorption capacity for fluoride among the metal ions tested in the case of SOJR [18, 19].

\section{Materials and Method}

\subsection{Chemicals and Instrumentation}

All the chemicals employed in this study were of pure reagent grade chemicals and used directly without further purification. Samples of sodium fluoride $(\mathrm{NaF})$, zirconium (IV) oxychloride octahydrate $\left(\mathrm{ZrOCl}_{2} * 8 \mathrm{H}_{2} \mathrm{O}\right)$ and sulfuric acid $\left(\mathrm{H}_{2} \mathrm{SO}_{4}, 96 \%\right)$ were purchased from Wako Chemical Co. Ltd., Japan. The stock solution $(1000 \mathrm{mg} / \mathrm{L})$ of fluoride was prepared by dissolving $1.05 \mathrm{~g}$ of $\mathrm{NaF}$ in $500 \mathrm{~mL}$ of deionized water. The working solutions were freshly prepared by diluting the stock solution at the time of experiment. The sample of the fluoride containing waste plating solution employed in this study was kindly provided by the Federation of Electro Plating Industry Association, Japan. For the $\mathrm{pH}$ adjustment, diluted nitric acid and sodium hydroxide $(0.1 \mathrm{M}$ each $(\mathrm{M}=\mathrm{mol} / \mathrm{L}))$, also purchased from Wako Chemicals Co. Ltd., Japan, were used. The $\mathrm{pH}$ of the solution was measured with the help of a TOA DKK, HM-30R pH meter. The elemental compositions of ATOJR before and after metal loading were measured by using an energy dispersive X-ray spectrometer (Shimadzu model, EDX-800HS). The total amount of $\mathrm{Zr}(\mathrm{IV})$ loaded onto ATOJR was measured after complete dissolution with aqua-regia by using an inductively coupled plasma atomic emission spectrometer (ICP-AES, Shimadzu model ICPS 8100). The concentration of fluoride before and after adsorption was measured by using an ion chromatography (Dionex model ICS-1500) equipped with separation column (IonPac AS12A, 4 x $200 \mathrm{~mm}$ ), guard column (IonPac AG 4 x $50 \mathrm{~mm}$ ) and automatic regenerating suppressor (A SRS $3004 \mathrm{~mm}$ ). 


\subsection{Preparation of the Adsorption Gel}

The OJR, obtained just after juicing, was provided by the JA Beverage Saga Co., Ltd., Japan and it was employed to prepare the ATOJR. To avoid the dissolution of the adsorbent in aqueous solutions, OJR was cross-linked by means of condensation reaction using concentrated sulfuric acid, where it was first washed several times using distilled water and dried in a convection oven at $343 \mathrm{~K}$, followed by grinding into fine powder using a Dalton model P-3S power mill. Fifteen grams of this fine powder of OJR was mixed together with 30 $\mathrm{mL}$ of concentrated sulfuric acid $(96 \%)$ in a $250 \mathrm{~mL}$ eggplant flask, followed by refluxing the mixture for $24 \mathrm{~h}$ at $373 \mathrm{~K}$ to achieve the cross-linking via condensation reaction. After 24 $\mathrm{h}$, the mixture was neutralized using sodium bicarbonate and the cross-linked product was separated by filtration using Advantec 5C $90 \mathrm{~mm}$ filter paper. It was further washed several times with distilled water until a neutral $\mathrm{pH}$, after which it was dried in a convection oven at $343 \mathrm{~K}$ overnight. To create the adsorption sites for fluoride, $\mathrm{Zr}$ (IV) was then loaded onto this prepared ATOJR, where $3 \mathrm{~g}$ of ATOJR was mixed together with $500 \mathrm{~mL}$ of $0.1 \mathrm{M} \mathrm{Zr(IV)} \mathrm{solution} \mathrm{at} \mathrm{pH} 2.23$, which was stirred for $24 \mathrm{~h}$ at $303 \mathrm{~K}$ for the loading reaction. The mixture was then filtered using the same filter paper and the filter cake was washed several times with distilled water to remove unadsorbed $\mathrm{Zr}(\mathrm{IV})$ ions and was dried in a convection oven at $343 \mathrm{~K}$. Thus prepared $\mathrm{Zr}(\mathrm{IV})$ loaded ATOJR is abbreviated as Zr-ATOJR hereafter.

\subsection{Loading Test of $\mathrm{Zr}(\mathrm{IV})$ Ion}

In order to evaluate the adsorption behavior of ATOJR for $\mathrm{Zr}(\mathrm{IV})$, its adsorption test was carried out batch wise at a solid liquid ratio of $1.5 \mathrm{~g} / \mathrm{L}$ by using $0.5 \mathrm{mM}$ of $\mathrm{Zr}(\mathrm{IV})$ solution at varying $\mathrm{pH}$. To investigate the maximum adsorption capacity for $\mathrm{Zr}(\mathrm{IV})$ ion, an adsorption isotherm test was carried out by varying the concentration of $\mathrm{Zr}$ (IV) ranging from 0.5 up to $11 \mathrm{mM}$ at $\mathrm{pH} 2.2$ at $303 \mathrm{~K}$. The percent loading and amount of $\mathrm{Zr}(\mathrm{IV})$ loaded onto the tested adsorbents were calculated according to the mass balance relationship expressed by equation (1) and (2), respectively.

$$
\begin{gathered}
\% A=\frac{C_{i}-C_{e}}{C_{i}} \times 100 \\
q=\frac{C_{i}-C_{e}}{W} \times V
\end{gathered}
$$

$\% A$ : percent loading of $\operatorname{Zr}(\mathrm{IV})$ loaded onto the tested adsorbents

$q$ : amount of $\mathrm{Zr}(\mathrm{IV})$ loaded onto the tested adsorbents

$C_{i}$ : initial concentrations of fluoride (mM)

$C_{e}$ : equilibrium concentrations of fluoride $(\mathrm{mM})$

$W$ : weight of the adsorbent (g-dry)

$V$ : volume of test solution (L)
Further, to evaluate the content of $\mathrm{Zr}(\mathrm{IV})$ in $\mathrm{Zr}$-ATOJR, $\mathrm{Zr}$-ATOJR was totally dissolved by mixing $50 \mathrm{mg}$ of the loaded adsorbent together with $10 \mathrm{~mL}$ of aqua regia, which was stirred for $24 \mathrm{~h}$ to ensure complete dissolution. After filtration, the concentration of $\mathrm{Zr}(\mathrm{IV})$ in the filtrate was measured using an ICP-AES.

\subsection{Adsorption Tests of Fluoride onto Zr-ATOJR}

Although equilibrium was found to be achieved within $2 \mathrm{~h}$ for all cases in the preliminary experiment, adsorbents and test solutions were shaken for $24 \mathrm{~h}$ in the subsequent adsorption test in order to ensure complete equilibrium. The adsorption test of fluoride ion was carried out by mixing $15 \mathrm{mg}$ of Zr-ATOJR together with $10 \mathrm{~mL}$ of $0.5 \mathrm{mM}$ fluoride solution at $303 \mathrm{~K}$ for $24 \mathrm{~h}$ at different $\mathrm{pH}$ to investigate the effect of $\mathrm{pH}$ on fluoride adsorption onto Zr-ATOJR, where dilute solutions of $\mathrm{HNO}_{3}$ or $\mathrm{NaOH}$ were used to adjust the $\mathrm{pH}$ of the fluoride solution. After filtration, the filtrate was analyzed for residual fluoride concentration by using an ion chromatography. The adsorption isotherms tests onto ATOJR and $\mathrm{Zr}$-ATOJR were carried out by mixing $15 \mathrm{mg}$ of the adsorbent together with $10 \mathrm{~mL}$ of fluoride solution for $24 \mathrm{~h}$ at varying initial concentrations of fluoride ion $(0.5-6 \mathrm{mM})$ at $\mathrm{pH} 4$. For the practical application of Zr-ATOJR, the removal of fluoride from actual waste plating solution was tested by mixing $10 \mathrm{~mL}$ of actual waste plating solution with different amount of Zr-ATOJR (5 - $100 \mathrm{mg}$ ), which was shaken for 24 $\mathrm{h}$ at $303 \mathrm{~K}$. The percentage adsorption and uptake capacity (q, $\mathrm{mmol} / \mathrm{g}$ ) were calculated according to equation (1) and (2), respectively.

\subsection{Desorption of Loaded Fluoride}

For the desorption test, fluoride loaded Zr-ATOJR was prepared by shaking $500 \mathrm{mg}$ of Zr-ATOJR together with 500 $\mathrm{mL}$ of fluoride solution $(0.63 \mathrm{mM})$ at $\mathrm{pH} 4$ for $24 \mathrm{~h}$ at $303 \mathrm{~K}$. After filtration, filtrate was analyzed for fluoride ion concentration by using an ion chromatography. The filter cake was washed several times with water to remove un-adsorbed fluoride and oven dried. The dried sample was used for the desorption tests.

The adsorbed fluoride was effectively desorbed from Zr-ATOJR by $\mathrm{NaOH}$ solution with insignificant leakage $(<1 \%)$ of the loaded $\mathrm{Zr}(\mathrm{IV})$. To identify the optimum concentration of $\mathrm{NaOH}, 25 \mathrm{mg}$ of fluoride loaded $\mathrm{Zr}$-ATOJR was stirred together with $10 \mathrm{~mL}$ of $\mathrm{NaOH}$ solution at varying concentration from 0.01 to $2 \mathrm{M}$ for $24 \mathrm{~h}$. After the filtration, filtrate was analyzed for fluoride ion concentration by using an ion chromatography. The percent desorption $(\% D)$ was calculated using equation (3).

$$
\% D=\left(D_{\mathrm{T}} / A_{\mathrm{T}}\right) \times 100
$$

$\% D$ : percent desorption of fluoride

$D_{\mathrm{T}}$ : amount of desorbed fluoride $(\mathrm{mg})$

$A_{\mathrm{T}}$ : amount of adsorbed fluoride (mg) 


\section{Results and Discussion}

\subsection{Characterization of the Adsorbent}

To identity the various functional groups contained in the adsorbent, analysis of a sample through FTIR spectra is an effective way of obtaining structural and bond information. Figure 1 shows the FTIR spectra of OJR and ATOJR before and after $\mathrm{Zr}(\mathrm{IV})$ loading. In the case of OJR, the feed material, sharp peaks were observed at around 3381, 2913, 1742 and $1683 \mathrm{~cm}^{-1}$ which are ascribed to the stretching vibration of $\mathrm{OH}, \mathrm{CH}_{2}, \mathrm{COO}$, and $\mathrm{C}=\mathrm{O}$ groups. The hydroxyl peaks observed at $3381 \mathrm{~cm}^{-1}$ was flattened or became wider after the acid treatment, which is attributed to the cross-linking condensation reaction between the hydroxyl groups of different polysaccharides in OJR, which was further confirmed by the appearance of new absorption band of C-O-C linkage at $1051 \mathrm{~cm}^{-1}$, suggesting that cross-linking reactions of different orange polysaccharides takes place by the treatment using concentrated sulfuric acid. In the case of Zr-ATOJR, the peaks at $1740 \mathrm{~cm}^{-1}$ observed in ATOJR, which is ascribed to carboxylic acid groups, completely disappeared while two new peaks ascribed to metal carboxylate, specifically zirconium carboxylate, were observed at around 1600 and $1398 \mathrm{~cm}^{-1}$, indicating that $\mathrm{Zr}$ (IV) ions were loaded onto the carboxylic acid functional groups of ATOJR during the loading reaction. The qualitative analysis of various elements present in the samples of ATOJR and Zr-ATOJR were carried out using EDX and the results are presented in figures 2 (a) and (b), respectively. As seen from figure. 2 (a), there appear the intense peaks of $\mathrm{C}, \mathrm{O}$, $\mathrm{Na}, \mathrm{Si}, \mathrm{P}, \mathrm{S}, \mathrm{K}, \mathrm{Ca}$, and Fe, whereas, after $\mathrm{Zr}(\mathrm{IV})$ loading, new peaks corresponding to $\mathrm{Zr}$ are appeared at energy values around $7.9,9.02$ and $9.41 \mathrm{keV}$ as shown in figure. 2 (b), which is one of the strong pieces of evidence that

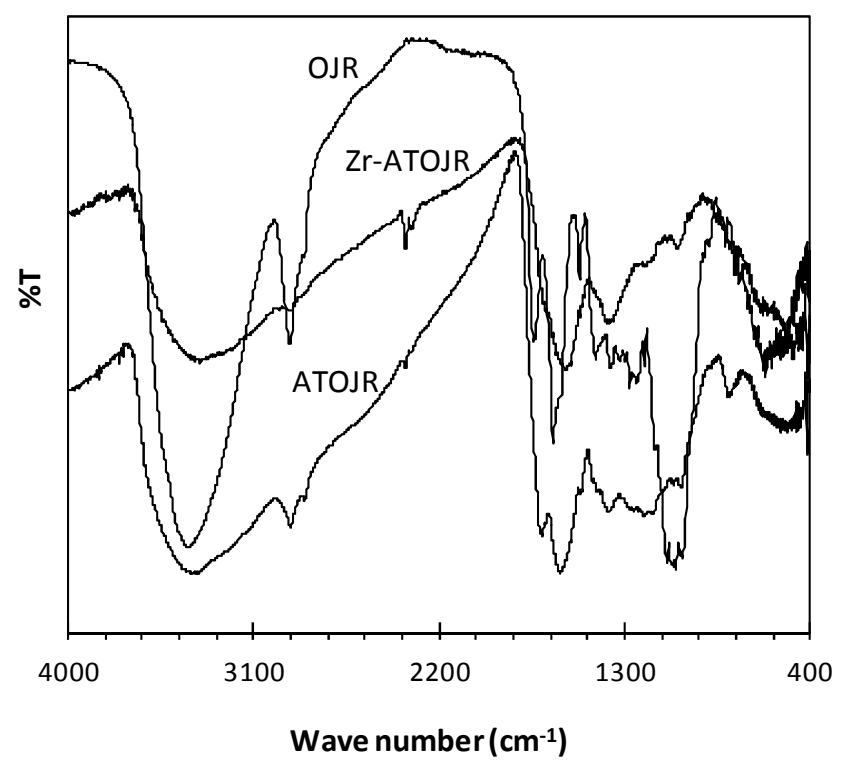

Figure 1. FTIR spectra of OJR, ATOJR ans Zr-ATOJR.

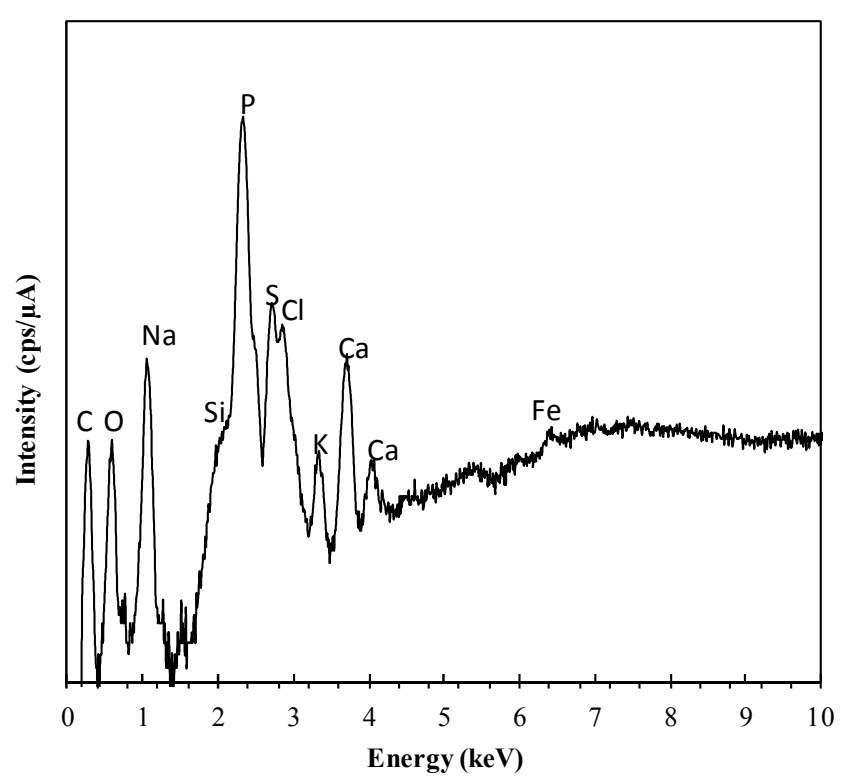

(a)

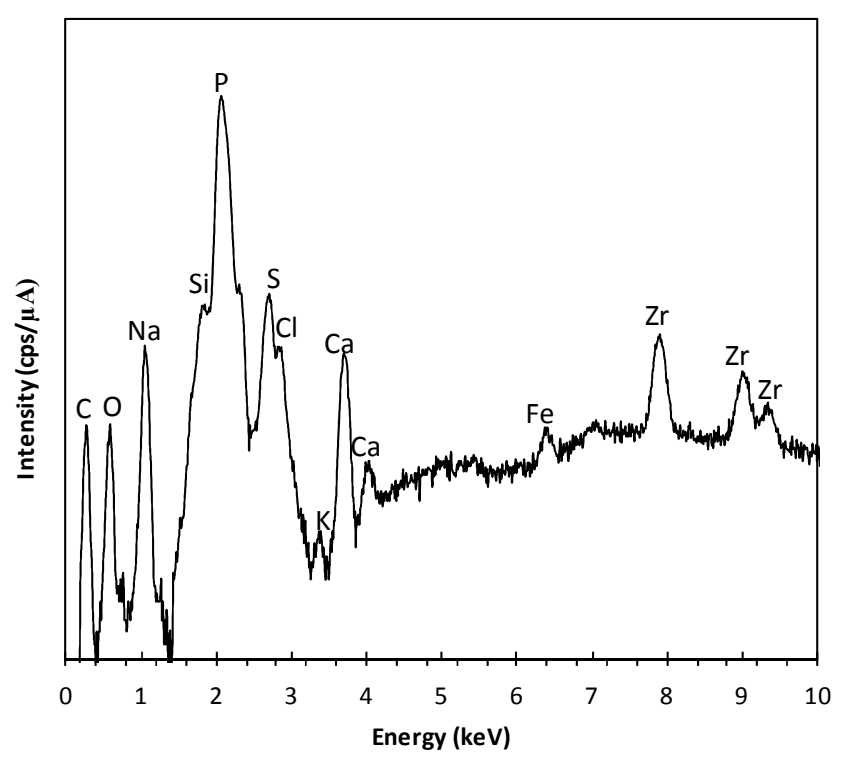

(b)

Figure 2. EDX spectra of ATOJR (a) and Zr-ATOJR(b).

ATOJR effectively adsorbed $\mathrm{Zr}(\mathrm{IV})$ ion. Figure 3 shows the XRD pattern of Zr-ATOJR where sharp peaks corresponding to crystalline structure are not observed, suggesting the amorphous nature of this adsorbent. Such an amorphous structure allows better accessibility of fluoride ions into the inside of adsorbent particle to reach adsorption sites by easy penetration. The existence of hydrated zirconium oxide in the sample of Zr-ATOJR was confirmed from the observation of broad peaks of hydrated zirconium oxide at $2 \theta$ values of $15-34$ and 40-61. Figure 4 shows the image of scanning electron micrograph (SEM) of ATOJR. It is evident from this figure that the surface of ATOJR is smooth and lacked any cracks or holes, suggesting a non-porous structure of ATOJR.

The amount of $\mathrm{Zr}(\mathrm{IV})$ loaded onto $\mathrm{Zr}$-ATOJR was evaluated to be $0.78 \mathrm{mmol} / \mathrm{g}$ by dissolving the sample of 
Zr-ATOJR in aqua regia at a solid/liquid ratio of $5 \mathrm{~g} / \mathrm{L}$, followed by the measurement of $\operatorname{Zr}(\mathrm{IV})$ concentration in the filtrate by using an ICP-AES.

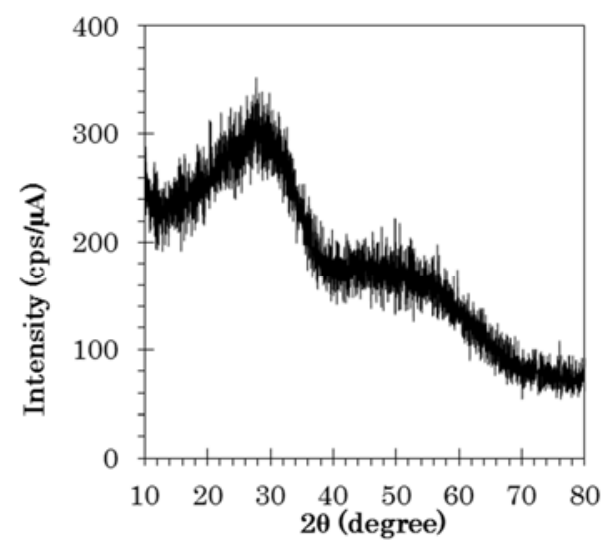

Figure 3. XRD pattern of Zr-ATOJR.

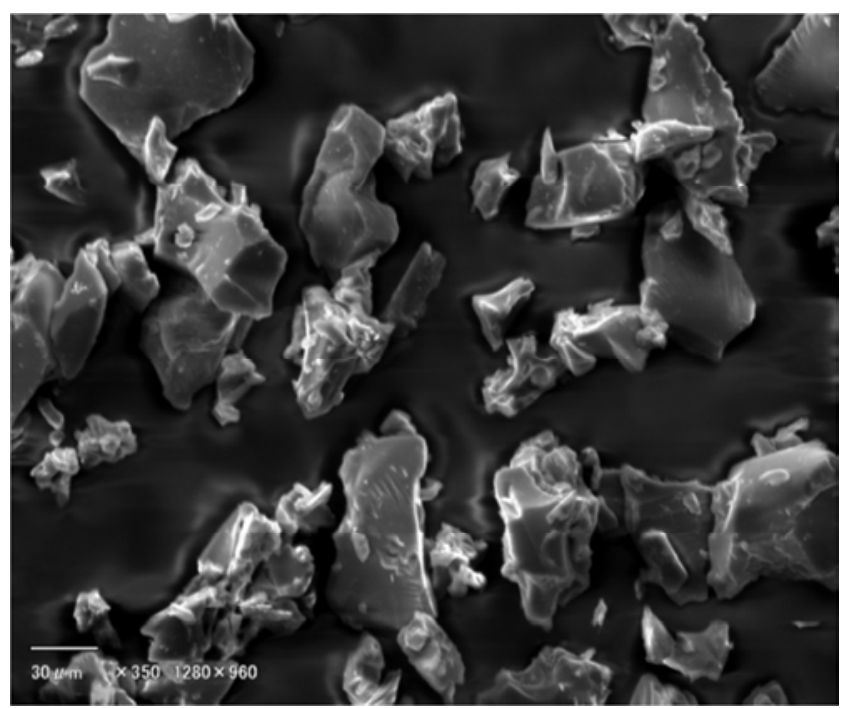

Figure 4. SEM image of ATOJR.Zr(IV).

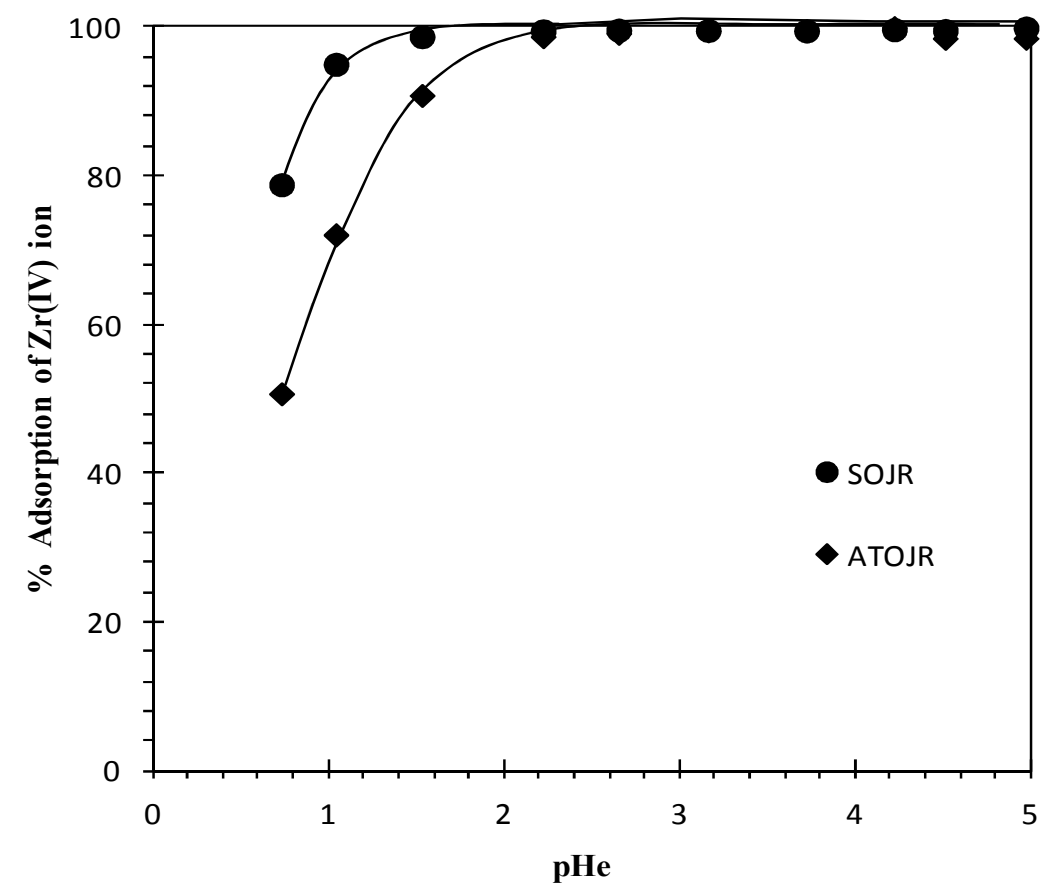

Conditions: concentration of $\operatorname{Zr}(\mathrm{IV})=0.5 \mathrm{mmol} / \mathrm{l}$, solid liquid ratio $=1.5 \mathrm{~g} / \mathrm{l}$, temperature $=303 \mathrm{~K}$, shaking time $=24 \mathrm{~h}$.

Figure 5. \% adsorption of $\mathrm{Zr}(I V)$ at different $\mathrm{pH}$ at equilibrium on ATOJR and SOJR for comparison.

\subsection{Loading Behavior of $\mathrm{Zr}(\mathrm{IV})$ onto ATOJR}

Because fluoride is adsorbed via $\mathrm{Zr}(\mathrm{IV})$ ion loaded onto ATOJR, adsorption behavior of $\mathrm{Zr}(\mathrm{IV})$ on ATOJR was investigated prior to the adsorption of fluoride on $\mathrm{Zr}$-ATOJR to find the optimum loading condition of $\mathrm{Zr}(\mathrm{IV})$ onto ATOJR. Figure 5 shows the\% adsorption of $\mathrm{Zr}(\mathrm{IV})$ onto ATOJR at varying $\mathrm{pH}$ at equilibrium together with that onto SOJR for comparison, which suggests that adsorption of $\mathrm{Zr}(\mathrm{IV})$ increased from $50.2 \%$ to $90.8 \%$ with increasing $\mathrm{pH}$ from 0.75 to 1.53 whereas more than $98 \%$ of was adsorbed at $\mathrm{pH} 2.2$, from which the loading of $\mathrm{Zr}$ (IV) was decided to be carried out at $\mathrm{pH}$ around 2.2 for the preparation of $\mathrm{Zr}$-ATOJR. Similarly, in the case of SOJR reported in the previous work [17], the adsorption of $\mathrm{Zr}(\mathrm{IV})$ was also increased from $78.5 \%$ to $97.3 \%$ by increasing $\mathrm{pH}$ from 0.74 to 1.56 and it was nearly $100 \%$ at around $\mathrm{pH} 2.2$, which is exactly the similar trend with that of ATOJR. 


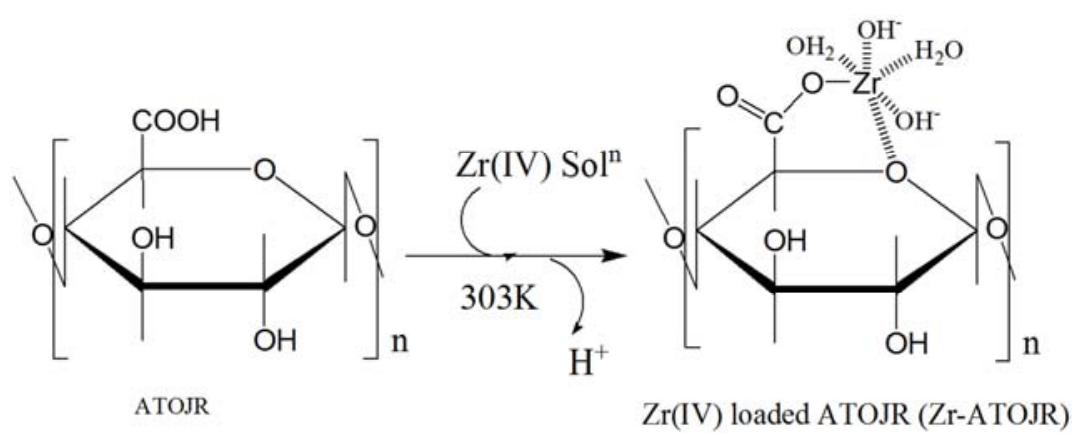

Figure 6. Loading mechanism of $\mathrm{Zr}(\mathrm{IV})$ ion onto ATOJR via exchange reaction.

The nature of increasing adsorption of $\mathrm{Zr}(\mathrm{IV})$ with increasing $\mathrm{pH}$ in both gels suggests that adsorption of $\mathrm{Zr}(\mathrm{IV})$ onto these adsorbents takes place in the same manner of cation exchange mechanism between hydrogen ions of carboxylic groups of pectic acid contained in ATOJR and SOJR and cationic $\mathrm{Zr}(\mathrm{IV})$ ion as depicted by Figure 6.

Further, $\mathrm{pH}$ of $\mathrm{Zr}(\mathrm{IV})$ solution after the adsorption on ATOJR was observed to be decreased, which is attributable to the release of hydrogen ions by this cation exchange reaction. For the determination of loading capacity of ATOJR for $\mathrm{Zr}(\mathrm{IV})$, adsorption isotherms of $\mathrm{Zr}(\mathrm{IV})$ on ATOJR was investigated by varying the $\mathrm{Zr}(\mathrm{IV})$ concentration $(0.5-11 \mathrm{mM})$ at $\mathrm{pH} 2.2$. It was found that adsorption of $\mathrm{Zr}(\mathrm{IV})$ on ATOJR increases with increasing equilibrium concentration of $\mathrm{Zr}(\mathrm{IV})$ at lower concentration and becomes constant or plateau at higher concentration, suggesting the Langmuir type monolayer adsorption of $\mathrm{Zr}(\mathrm{IV})$ by ATOJR. From this adsorption isotherm test, the maximum loading capacity of ATOJR for $\mathrm{Zr}(\mathrm{IV})\left(\mathrm{q}_{\max }\right.$, $\mathrm{mmol} / \mathrm{g}$ ) was evaluated as $0.83 \mathrm{mmol} / \mathrm{g}$, which is inferior to those of SOJR ( $=1.62 \mathrm{mmol} / \mathrm{g}[19])$ and DOJR ( $=0.90 \mathrm{mmol} / \mathrm{g}$ [20]). Such difference in the loading capacity is inferred to be ascribed to the treatment of OJR; i.e. in the cases of SOJR and DOJR, number of functional groups of pectic acid effective for metal loading is increased by saponification reaction using calcium hydroxide whereas it is decreased by condensation reaction using concentrated sulfuric acid between functional groups of pectic acid and those of cellulose. The loading capacity for $\mathrm{Zr}(\mathrm{IV})$ directly affects the adsorption capacity for fluoride as will be mentioned later.

\subsection{Effect of pH and Adsorption Mechanism of Fluoride}

Figure 7 shows the effect of equilibrium $\mathrm{pH}$ on the adsorption of fluoride onto ATOJR and Zr-ATOJR as well as $\mathrm{Zr}$-SOJR for comparison at varying $\mathrm{pH}$ ranging from 2 up to 12. As seen in this figure, adsorption of fluoride is markedly dependent on $\mathrm{pH}$ for all cases. It is slightly increased with increasing $\mathrm{pH}$ in the $\mathrm{pH}$ range $1-4$, and decreased sharply at higher $\mathrm{pH}$. Maximum adsorption of fluoride is found to occur at $\mathrm{pH}$ around 4-5 for all cases. It is evidently observed that the adsorption is improved drastically after $\mathrm{Zr}$ (IV) loading, which is attributed to the development of new adsorption sites caused by the loaded $\mathrm{Zr}(\mathrm{IV})$ in addition to those based on $\mathrm{Ca}$ for anionic species of fluoride as described as follows. From elementally analysis shown in fugure 2(a), ATOJR itself contains some metal ions like $\mathrm{Na}, \mathrm{Si}, \mathrm{K}, \mathrm{Ca}$, and $\mathrm{Fe}$ which may be bonded to orange pectic acid to form metal pectate.

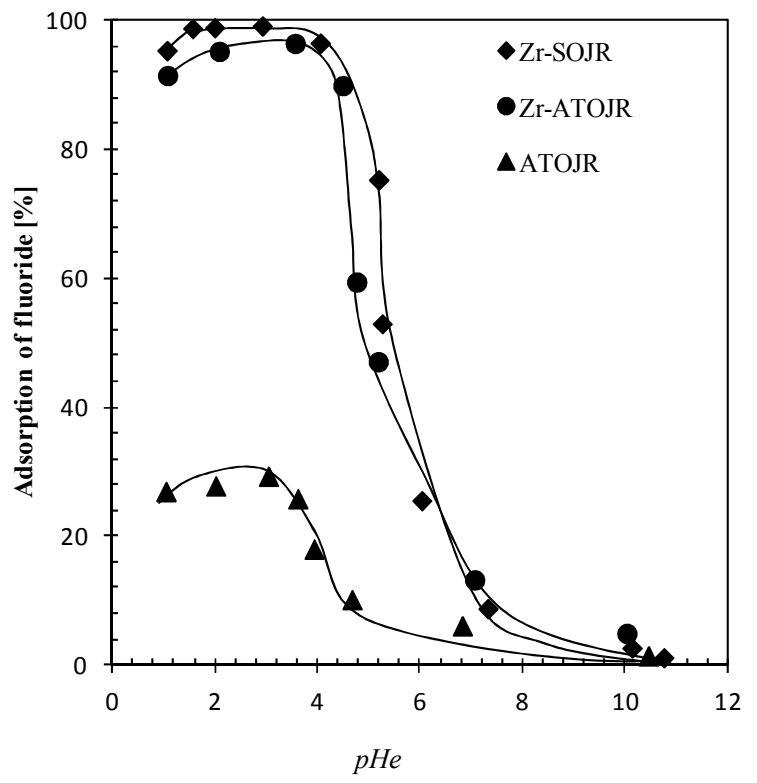

Figure 7. Influence of $\mathrm{pH}$ at equilibrium on\% adsorption of fluoride on ATOJR and Zr-ATOJR. Conditions: fluoride solution $=0.5 \mathrm{mmol} / \mathrm{l}$, solid-liquid ratio $=1.5 \mathrm{~g} / \mathrm{l}$, temperature $=303 \mathrm{~K}$, shaking time $=24 \mathrm{~h}$.

Among these metal ions, Ca exhibits some affinity towards fluoride ion where adsorption of fluoride takes place by electrostatic interaction between positive charged calcium ion contained in ATOJR and fluoride fluoride ion as shown below.

$$
\text { Polymer }=\mathrm{COO}^{\delta-} . . \mathrm{Ca}^{\delta+}+\mathrm{F}^{-} \rightarrow \text { Polymer }=\mathrm{COO}^{\delta-}-\mathrm{Ca}^{\delta+} . . \mathrm{F}^{\delta-}
$$

The $\mathrm{pH}$ effect on the adsorption on Zr-ATOJR quite resembles that on $\mathrm{Zr}$-SOJR. Because adsorption behavior of anionic species onto metal-loaded adsorbents is governed by the nature of the loaded metal ions, this tendency is considered to be natural. In the case of Zr-ATOJR and Zr-SOJR, the \% adsorption of fluoride reaches $91.3 \%$ and $97.3 \%$, respectively, at $\mathrm{pH}$ around 1 which was observed to be increased with increasing $\mathrm{pH}$ reaching a maximum at $\mathrm{pH}$ around 3-4, where more than $98 \%$ removal of fluoride was achieved in both the cases. It was gradually decreased with a further increase in $\mathrm{pH}$ of the solution and no or negligible adsorption of fluoride was observed at $\mathrm{pH}$ higher than 10 for all three kinds of adsorbents tested. With increasing $\mathrm{pH}$, concentration of hydroxyl ion that 
potentially competes with fluoride ions during adsorption process increases, which results in the decrease in adsorption of fluoride. Because, at $\mathrm{pH}$ lower than 2 , more than $95 \%$ of fluoride exists in the form of nonionic form, i.e. hydrofluoric acid (HF), which was hardly adsorbed onto these adsorbents, the adsorption is ultimately decreased. Similar observations have been also reported on the adsorption behavior of other $\mathrm{Zr}(\mathrm{IV})$ loaded adsorbents, such as $\mathrm{Zr}$ (IV) loaded leather fiber [21], $\mathrm{Zr}$ (IV) loaded cross-linked seaweed [22] and $\mathrm{Zr}(\mathrm{IV})$ loaded carboxylated chitosan [23], which is attributable to the fact that all of these adsorbents employ $\mathrm{Zr}(\mathrm{IV})$ as the loaded metal ion, as mentioned earlier. Consequently, the adsorption mechanism of fluoride on Zr-ATOJR can be clearly interpreted similarly to the case of Zr-SOJR by the following reactions.

$$
\text { Polymer } \equiv \mathrm{Zr}-\mathrm{OH}+\mathrm{F}^{-} \rightarrow \text { Polymer } \equiv \mathrm{Zr}-\mathrm{F}+\mathrm{OH}^{-}
$$

In the case of loading high valent metal ion like $\mathrm{Zr}(\mathrm{IV})$ onto the polymer matrix of orange pectic acid, the neutralization of all the positive charge of $\mathrm{Zr}(\mathrm{IV})$ only by the carboxylic groups of pectic acid contained in ATOJR or SOJR is impossible because of steric hindrance caused by large polymers of orange pectic acid. Consequently, some of the positive charges of $\mathrm{Zr}$ (IV) are neutralized by hydroxyl ions in aqueous solution. These hydroxyl ions are considered to be exchanged with fluoride ions during fluoride adsorption according to the ligand exchange reaction as shown above.

\subsection{Adsorption Isotherm of Fluoride}

Figure 8(a) presents the adsorption isotherms of fluoride on Zr-ATOJR at varying temperatures from 303 to $323 \mathrm{~K}$, as well as that on ATOJR at $303 \mathrm{~K}$, for comparison. The result shows that the adsorption of fluoride increases with increasing fluoride ion concentration at low concentration while it tends to approach constant values in all the cases at high concentration and it increases with increasing temperature, suggesting an endothermic nature of adsorption which was further proved by calculating thermodynamic parameters in the later section.

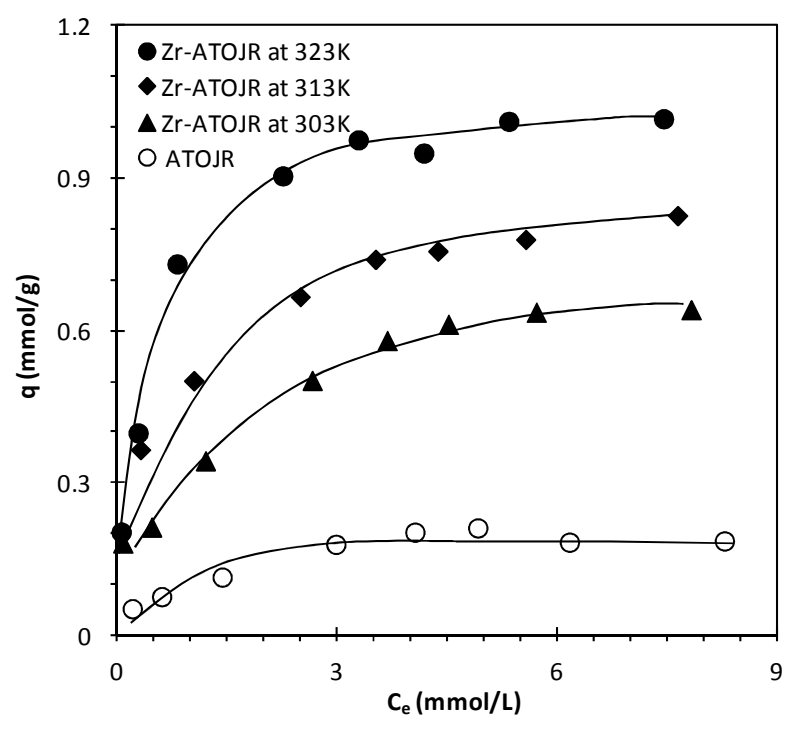

(a). Adsorption isotherm.

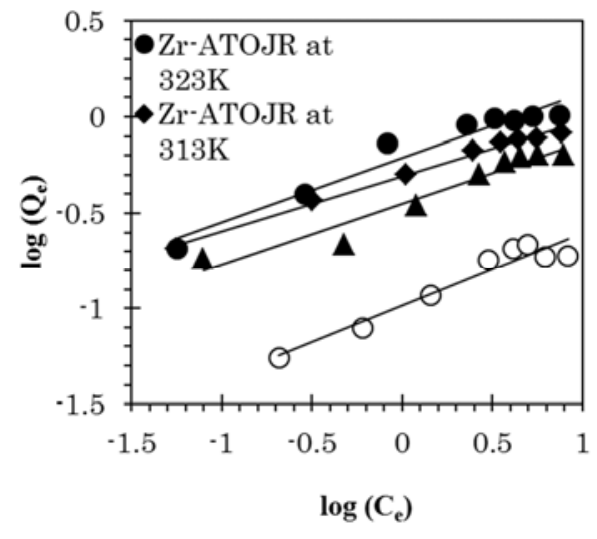

(b). Fruindrich plot.

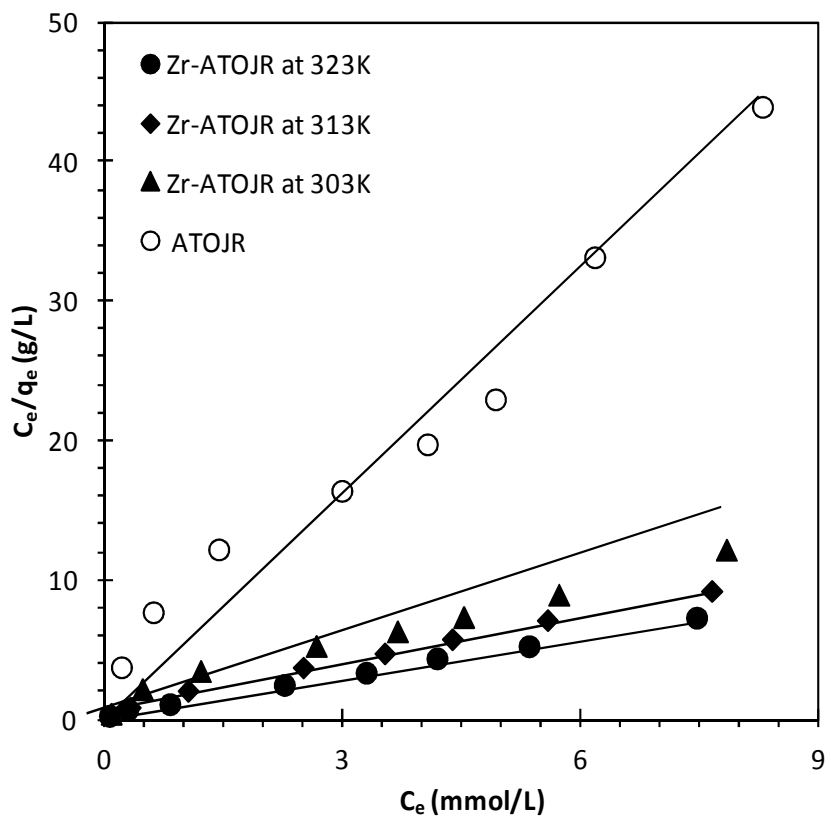

(c). Langmuir plot.

Figure 8. Adsorption Isotherm.

Adsorption isotherm of fluoride on $\mathrm{Zr}$-ATOJR at varying temperatures and on ATOJR at $303 \mathrm{~K}$. Conditions: $\mathrm{pH}=4$, volume of solution $=10 \mathrm{ml}$, weight of adsorbent $=15 \mathrm{mg}$, shaking time $=24 \mathrm{~h}$.

Freundlich and Langmuir adsorption isotherm equations expressed by equations (4) and (5), respectively, were used to interpret these experimental results.

$$
\log q_{\mathrm{e}}=\log K_{F}+(1 / n) \log C_{\mathrm{e}}
$$

$C_{\mathrm{e}}$ : equilibrium concentration of fluoride in solution ( $\left.\mathrm{mM}\right)$ $q_{\mathrm{e}}$ : amount of fluoride adsorbed per unit mass of adsorbent at equilibrium $(\mathrm{mmol} / \mathrm{g})$

$K_{F}$ and $n$; Freundlich constants related to the adsorption capacity and adsorption intensity.

The values $K_{F}$ and $n$ can be calculated from the intercept and slope of the linear Freundlich plot of $\log q_{\mathrm{e}}$ versus $\log C_{\mathrm{e}}$ as shown in Figure 8(b). Thus evaluated values are listed in table 1. On the other hand, the Langmuir isotherm model assumes monolayer coverage where all the active adsorption 
sites have equal affinity for adsorbate molecules.

$$
C_{\mathrm{e}} / q_{\mathrm{e}}=1 / q_{\max } b+C_{\mathrm{e}} / q_{\max }
$$

$q_{\max }:$ maximum adsorption capacity of the adsorbent for fluoride ion $(\mathrm{mmol} / \mathrm{g})$

$b$ : adsorption equilibrium constant related to the free energy change during adsorption process $(\mathrm{L} / \mathrm{mmol})$

The values of $q_{\max }$ and $\mathrm{b}$ were evaluated from the slope and intercept of the linear plot of $C_{\mathrm{e}} / q_{\mathrm{e}}$ versus $C_{\mathrm{e}}$ as shown in Figure $8(\mathrm{c})$, which are also listed in Table 1. From this table, it is evident that all experimental data are more satisfactorily fitted with the Langmuir isotherm with a higher correlation coefficient $\left(\mathrm{r}^{2}=0.99\right)$ than the Freundlich isotherm model $\left(r^{2}<0.91\right)$, suggesting that the Langmuir isotherm model is suitable for the modeling of this adsorption system; that is, it can be concluded that the adsorption of fluoride onto ATOJR and Zr-ATOJR takes place according to the Langmuir's monolayer adsorption model. From the comparison of the maximum fluoride uptake capacity of ATOJR with that on $\mathrm{Zr}$-ATOJR at $303 \mathrm{~K}$, it is found to be drastically improved after $\mathrm{Zr}$ (IV) loading (from 0.21 up to $0.71 \mathrm{mmol} / \mathrm{g}$ ) also as mentioned earlier, which is attributable to the development of more active adsorption sites on ATOJR by $\mathrm{Zr}$ (IV) loading. A similar type of adsorption behavior was observed in the case of Zr-SOJR in our previous study [19], indicating similar types of adsorption mechanism may take place in both the cases. From the temperature dependency of the adsorption of fluoride on Zr-ATOJR, the thermodynamic parameters were calculated. That is, from the Langmuir's adsorption equilibrium constants, b, at different temperatures, thermodynamic parameters such as Gibbs free energy change, enthalpy change and entropy change were calculated according to the following relationships:

Table 1. Langmuir and Frundlich isotherm parameters for the adsorption of fluoride onto Zr-ATOJR at different temperatures and its comparison with ATOJR itself.

\begin{tabular}{lllll}
\hline $\begin{array}{l}\text { Adsorbents and } \\
\text { temperature }\end{array}$ & $\mathbf{p H}$ & \multicolumn{4}{l}{ Langmuir parameters } \\
\hline & & $\boldsymbol{q}_{\max }(\mathbf{m m o l} / \mathbf{g})$ & $\boldsymbol{b}(\mathbf{L} / \mathbf{m m o l})$ & $\mathbf{r}^{\mathbf{2}}$ \\
\hline Zr-ATOJR at 303K & 4 & 0.71 & 1.14 & 0.98 \\
Zr-ATOJR at 313K & 4 & 0.86 & 2.19 & 0.99 \\
Zr-ATOJR at 323K & 4 & 1.05 & 3.36 & 0.99 \\
ATOJR at 303K & 4 & 0.21 & 1.40 & 0.98 \\
Adsorbents and & $\mathbf{p H}$ & Freudlich parameters & \\
temperature & & $\boldsymbol{K}_{\boldsymbol{F}}$ & $\boldsymbol{b}$ & $\mathbf{r}^{\mathbf{2}}$ \\
& 4 & 0.71 & 1.14 & 0.98 \\
Zr-ATOJR at 303K & 4 & 0.86 & 2.19 & 0.99 \\
Zr-ATOJR at 313K & 4 & 1.05 & 3.36 & 0.99 \\
Zr-ATOJR at 323K & 4 & 0.21 & 1.40 & 0.98 \\
ATOJR at 303K & & & & \\
\hline
\end{tabular}

$$
\begin{aligned}
& \Delta G=\Delta H-T \Delta S \\
& \Delta G=-\mathrm{R} T \ln b
\end{aligned}
$$

$\Delta G$ : Gibbs free energy change $(\mathrm{kJ} / \mathrm{mol})$

$\Delta H$ : enthalpy change $(\mathrm{kJ} / \mathrm{mol})$

$\Delta S$ : entropy change $(\mathrm{kJ} / \mathrm{mol} \mathrm{K})$

$\mathrm{R}$ : gas constant $(\mathrm{kJ} / \mathrm{mol} \mathrm{K})$

\section{$T$ : temperature $(\mathrm{K})$}

Combination of equations (6) and (7) gives

$$
\ln b=-\Delta H / \mathrm{R} T+\Delta S / \mathrm{R}
$$

Gibbs free energy change $(\Delta G)$ of the system for all temperatures were evaluated according to equation (7) as $-0.34,-2.05$ and $-3.27 \mathrm{~kJ} / \mathrm{mol}$ for 303,313 and $323 \mathrm{~K}$, respectively. On the other hand, enthalpy change $(\Delta H)$ and entropy change $(\Delta S)$ were determined as $44.03 \mathrm{~kJ} / \mathrm{mol}$ and $146.7 \mathrm{~J} / \mathrm{mol} \mathrm{K}$, respectively, from the slope and intercept of the Van't Hoff plot of $\ln b$ versus $1 / T$, respectively, according to equation (8) as shown in Figure 9. The value of $\Delta G$ is negative for all the temperature and is decreased with the increase in temperature, indicating that the adsorption of fluoride on Zr-ATOJR is spontaneous at the tested range of temperatures. The positive value of enthalpy change confirms that the adsorption is endothermic in nature, whereas the positive value of entropy change suggests that the adsorption process leads to an increase in disorderness or randomness at the solid surface during the adsorption, which is possibly due to the release of coordinated hydroxyl ions via. ligand exchange reaction with fluoride ion during adsorption process.

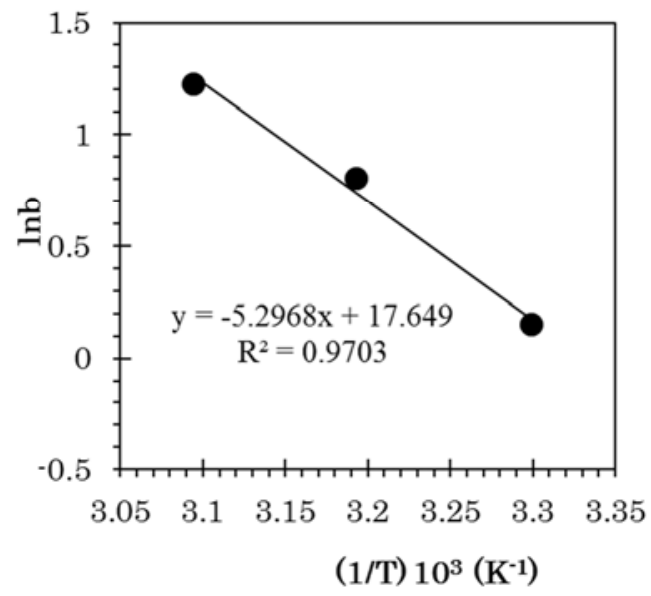

Figure 9. Vant Hoff's plot for the adsorption of fluoride on Zr-ATOJR.

\subsection{Desorption of Loaded Fluoride}

The desorption of fluoride from Zr-ATOJR is important to determine the extent of its recovery in addition to the regeneration of the adsorbents for repeated use. As shown in Figure 6, because negligible adsorption of fluoride on $\mathrm{Zr}$-ATOJR is observed at $\mathrm{pH}$ higher than 10 , dilute alkaline solutions are the candidate for the desorption of fluoride. Based on such expectation, the optimization of $\mathrm{NaOH}$ concentration was carried out by using varying concentration of $\mathrm{NaOH}$ (from 0.001 to $0.5 \mathrm{M}$ ) as shown in Figure 10. From the result shown in this figure, $0.1 \mathrm{M} \mathrm{NaOH}$ solution was found to be the optimum concentration to effectively desorb fluoride from the loaded adsorbent. 


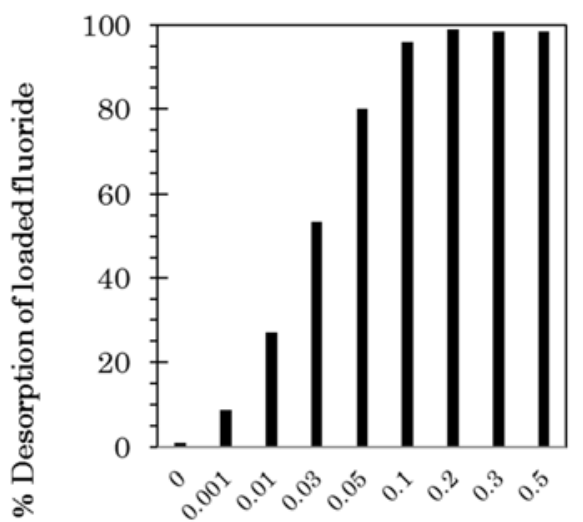

\section{$\mathrm{NaOH}(\mathrm{M})$}

Figure 10. Desorption of fluoride from fluoride loaded Zr-ATOJR using varying concentrations of $\mathrm{NaOH}$ solution.

Conditions: amount of fluoride contained in fluoride loaded $\mathrm{Zr}-\mathrm{ATOJR}=12.8 \mathrm{mg} / \mathrm{g}$, solid liquid ratio $=2.5 \mathrm{~g} / \mathrm{l}$, shaking time $=24 \mathrm{~h}$, temperature $=303 \mathrm{~K}$

The desorption of fluoride is inferred to take place by the replacement of adsorbed fluoride by hydroxyl ions provided from $\mathrm{NaOH}$ solution as shown below.

$$
\text { Polymer } \equiv \mathrm{M}-\mathrm{F}+\mathrm{OH}^{-} \rightarrow \text { Polymer } \equiv \mathrm{M}-\mathrm{OH}+\mathrm{F}^{-}
$$

\subsection{Application of Zr-ATOJR to Remove Fluoride from Actual Waste Plating Solution}

To evaluate the feasibility of Zr-ATOJR for the treatment of industrial waste water containing trace concentration of fluoride ion, the adsorption behavior for fluoride was investigated using actual waste plating solution containing several cationic species $\left(\mathrm{Al}^{3+}: 12.7 \mathrm{mg} / \mathrm{L}, \mathrm{Ca}^{2+}: 28.9 \mathrm{mg} / \mathrm{L}\right.$, $\mathrm{Si}^{4+}: 37.5 \mathrm{mg} / \mathrm{L}, \mathrm{Fe}^{3+}: 21.6 \mathrm{mg} / \mathrm{L}, \mathrm{Cu}^{2+}: 8.1 \mathrm{mg} / \mathrm{L}$ and $\mathrm{Zn}^{2+}$ : $0.83 \mathrm{mg} / \mathrm{L})$ as well as anionic species $\left(\mathrm{F}^{-}: 15.2 \mathrm{mg} / \mathrm{L}\right.$ and $\mathrm{SO}_{4}{ }^{2-}$ : $524 \mathrm{mg} / \mathrm{L}$ ) by using $\mathrm{Zr}$-ATOJR at varying solid liquid ratio.

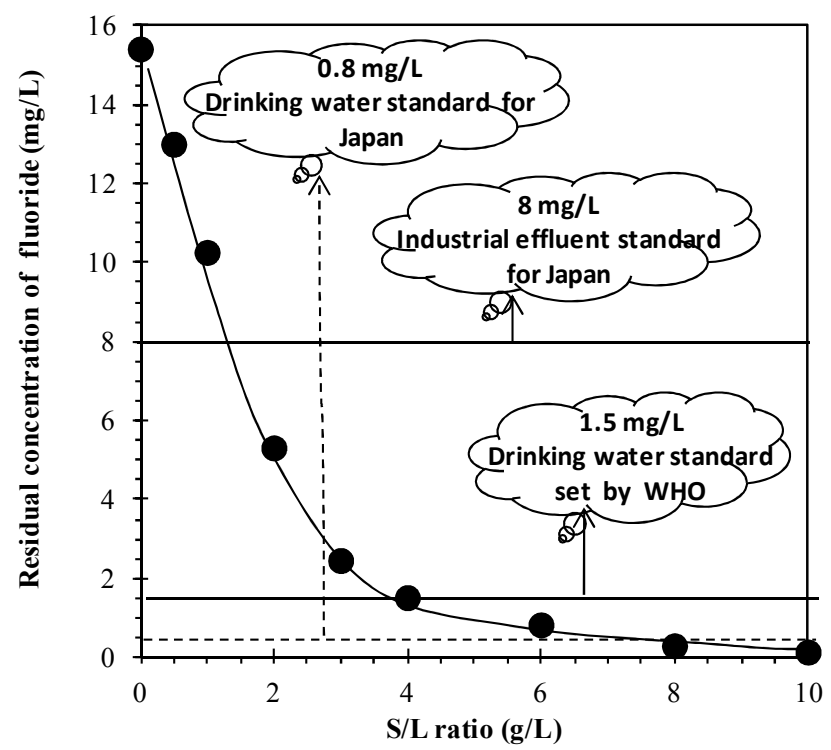

Figure 11. Application of Zr-ATOJR for the removal of trace concentration of fluoride from actual waste plating solution at different solid-liquid ratio.
Conditions: $\mathrm{pH}=6.7$, fluoride concentration $=15.2 \mathrm{mg} / \mathrm{l}$, volume of test solution $=10 \mathrm{ml}$, shaking time $=24 \mathrm{~h}$, temperature $=303 \mathrm{~K}$.

Figure 11 shows the residual concentration of fluoride ions in the waste plating solution after the adsorption onto $\mathrm{Zr}$-ATOJR at varying solid liquid ratio at its native $\mathrm{pH}(\mathrm{pH}$ $=6.7$ ). It is evident from this figure that fluoride removal was increased with increasing solid liquid ratio and fluoride concentration was found to be lowered less than industrial effluent standard in Japan $(8 \mathrm{mg} / \mathrm{L})$ at the solid liquid ratio of $1 \mathrm{~g} / \mathrm{L}$. It also suggests that, at the solid liquid ratio higher than 4 and $6 \mathrm{~g} / \mathrm{L}$, the maximum permissible level of fluoride in drinking water set by WHO $(1.5 \mathrm{mg} / \mathrm{L})$ and Japanese environmental standard $(0.8 \mathrm{mg} / \mathrm{L})$ can be cleared, respectively, whereas more than $8 \mathrm{~g} / \mathrm{L}$ of solid liquid ratio is required to achieve $100 \%$ removal. Furthermore, since zirconium leakage from the gel was found to be very insignificant in this case, Zr-ATOJR investigated in this study can be expected as an excellent adsorption material to treat the waste plating solution containing trace amount of fluoride ion.

\subsection{Comparative Studies with Other Adsorbents}

Table 2 shows the comparison of maximum adsorption capacities of ATOJR and Zr-ATOJR investigated in this study with other adsorbents including Zr-SOJR reported in the literatures. Although the maximum adsorption capacities listed in this table were evaluated at different $\mathrm{pH}$ and different temperatures, they can be useful criteria for the comparison of adsorption capacity for process design in the actual operation in large industrial scale. It is clear from this table that the maximum adsorption capacity of Zr-ATOJR investigated in this work is higher than the majority of the adsorbents reported in the literature. The adsorption capacity of some metal loaded adsorbents like La-200CT, READF-(PG) and mixed rare earth oxide exhibits higher adsorption capacity for fluoride ions than Zr-ATOJR. Compared also with Zr-SOJR which uses the same feed material, orange juice residue (OJR), the maximum adsorption capacity on $\mathrm{Zr}$-ATOJR $(0.71 \mathrm{mmol} / \mathrm{g})$ is lower than that on Zr-SOJR $(1.20 \mathrm{mmol} / \mathrm{g})$ at $303 \mathrm{~K}$. This difference is attributable to the difference in the loading capacity for $\mathrm{Zr}(\mathrm{IV})$ between SOJR and ATOJR; i.e. that for SOJR is 1.62 $\mathrm{mmol} / \mathrm{g}$ [17] while that for ATOJR is $0.83 \mathrm{mmol} / \mathrm{g}$. This difference in the loading capacity is considered to be caused by the difference of the

treatments for OJR; i.e. functional groups of pectin (partly methyl-esterified pectic acid) are effectively saponified into pectic acid resulting in the increase in the number of metal bonding sites in the treatment of SOJR while, in the treatment of ATOJR, some of functional groups of pectin undergo the condensation reaction each other and together with other polysaccharides such as cellulose losing the sites for bonding metal ions though some of pectin functional groups are hydrolyzed into pectic acid by the aid of sulfuric acid. However, high-porous resins like READF-(PG) and La(III) loaded 200CT resins suffer from serious drawback of clogging of micro-pores of the resins by fine particles present in the fluoride containing waste water. The direct application of 
mixed rare earth metal oxide looks more costly. In the case of $\mathrm{Zr-SOJR}$, because it is prepared from wet orange juice residue, it should be prepared immediately after juicing to avoid decaying and, further, it requires much water washing as mentioned earlier accompanying the generation of large amount of waste water, which potentially increases the production cost of the adsorbent. Alternatively, Zr-ATOJR investigated in this study can be prepared from dried orange juice residue where more than $70 \%$ of waste water generation was reduced by cross-linking using sulfuric acid in addition to the $100 \%$ removal efficiency of fluoride from actual waste plating solution. Hence it appears more promising as a potential alternative for the treatment of fluoride polluted water.

Table 2. Comparison of the maximum adsorption capacities on Zr-ATOJR at varying temperatures and those of various adsorbents for fluoride ion.

\begin{tabular}{llll}
\hline Adsorbents & pH & $\begin{array}{l}\boldsymbol{q}_{\max } \\
{[\mathbf{m m o l} / \mathbf{g}]}\end{array}$ & Ref. \\
\hline Zr-ATOJR at 323K & 4 & 1.05 & This work \\
Zr-ATOJR at 313K & 4 & 0.86 & This work \\
Zr-ATOJR at 303K & 4 & 0.71 & This work \\
ATOJR at 303K & 4 & 0.21 & This work \\
Zr(IV) loaded SOJR at 303K & 2.4 & 1.20 & {$[19]$} \\
Zr(IV) loaded DOJR at 303K & 4 & 1.43 & {$[20]$} \\
La(III) loaded 200CT resin at 303K & 6 & 1.34 & {$[24]$} \\
Waste carbon slurry & 7.5 & 0.23 & {$[25]$} \\
Spirogyra species IO1 & 7 & 0.06 & {$[26]$} \\
Synthetic nano-hydroxyapatite & $5-6$ & 0.24 & {$[27]$} \\
Fe(III) loaded cotton cellulose & 4 & 0.98 & {$[28]$} \\
Alumina/chitosan composite & 7 & 0.20 & {$[29]$} \\
KMnO modified rice straw carbon & 2 & 0.84 & {$[30]$} \\
Zr impregnated coconut shell carbon & 4 & 0.19 & {$[31]$} \\
READF & 3 & 2.10 & {$[32]$} \\
Acid activated mud & 5 & 0.15 & {$[33]$} \\
Carboxylated crosslinked chitosan & 7 & 0.58 & {$[23]$} \\
Montmorilonite & 6 & 0.01 & {$[34]$} \\
Nano-hydroxyapatite/chitosan & 7 & 0.11 & {$[35]$} \\
Quick lime & - & 0.87 & {$[36]$} \\
\hline
\end{tabular}

\section{Conclusion}

Efficient adsorbent for fluoride was prepared by loading $\mathrm{Zr}(\mathrm{IV})$ onto OJR treated with concentrated sulfuric acid. The adsorption behavior of ATOJR for fluoride was drastically improved by loading $\mathrm{Zr}(\mathrm{IV})$ on ATOJR. This adsorption was found to be strongly $\mathrm{pH}$ dependent; i.e. nearly quantitative adsorption was observed at $\mathrm{pH}$ range 2-4 while only negligible adsorption was observed at $\mathrm{pH}$ greater than 10 . From the adsorption isotherm study, the adsorption can be interpreted in terms of the Langmuir's monolayer adsorption theory. Thermodynamic study suggested that adsorption of fluoride is spontaneous and endothermic in nature. Fluoride loaded on Zr-ATOJR can be effectively desorbed by dilute alkali solutions. Adsorption/desorption mechanism was interpreted by the anion exchange between hydroxyl and fluoride ions. The Zr-ATOJR was found to be successfully applied for the removal of trace concentration of fluoride from actual waste plating solution.

\section{References}

[1] Jha SK, Nayak AK, Sharma YK. (2009). Fluoride toxicity effect in onion (Allium cepal.) grown in contaminated soils. Chemosphere, 76: 353-356.

[2] Versessinina Y, Trapido M, Ahelik V, Munter R. (2001). Fluoride in drinking water: The problem and its possible solution. Proc. Estonian Acad. Sci. Chem., 50: 81-88, 2001.

[3] Huang CJ, Liu JC. (1999). Precipitate floatation of fluoride containing wastewater from semiconductor manufacturer. Water Res., 33: 3403-3412.

[4] Turner BD, Binning P, Stipp SLS. (2005) Fluoride removal by calcite: Evidence for fluoride precipitation and surface adsorption. Env. Sci. Technol., 39: 9561-9568.

[5] Samatya S, Mizuki H, Ito Y, Kawakita H, Uezu K. (2010). The effect of polystyrene as a progen on the fluoride ion sorption of $\mathrm{Zr}^{4+}$-surface immobilized resin. React. Funct. Polym., 70: 63-68.

[6] Wajima T, Umeta Y, Narita S, Sugawara K. (2009). Adsorption behavior of fluoride ion using a titanium hydroxide derived adsorbent. Desalination, 249: 323-330.

[7] Xu X, Burgess JO. (2003). Compressive strength, fluoride release and recharge of fluoride-releasing materials. Biomaterials, 24: 2451-2461.

[8] Fan X, Parker DJ, Smith MD. (2003). Adsorption kinetics of fluoride on low cost materials. Water Res., 37: 4929-4937, 2003.

[9] Meenakshi, Maheshwari RC. (2006). Fluoride in drinking water and its removal. J. Hazard. Mater., B137: 456-463

[10] Durmaz F, Kara H, Cengeloglu Y, Ersoz M. (2005). Fluoride removal by Donnan dialysis with anion exchange membranes. Desalination, 177: 51-57.

[11] Wioeniewski J, Rozanska A. (2007). Donnan dialysis for hardness removal from water before electodialytic desalination. Desalination, 212: 251-260.

[12] Zhang G, Gao Y, Zhang Y, Gu P. (2005). Removal of fluoride from drinking water by membrane coagulation reactor. Desalination, 177: 143-155.

[13] Volesky B. (1990). Biosorption of Heavy Metals. CRC Press, Boca Raton, USA.

[14] Marques PA, Pinherro HM, Teixeria JA, Rosa MF. (1999). Removal efficiency of $\mathrm{Cu}^{2+}, \mathrm{Cd}^{2+}$ and $\mathrm{Pb}^{2+}$ by waste brewery biomass: $\mathrm{pH}$ and cation association effects. Desalination, 124: 137-144.

[15] Ifuku Y. (1997). Production of juice from citrus fruits, In: Japan Fruit Juice Association (eds.): Novel Encyclopedia of Fruit Juices (in Japanese), Asakura Shoten Co.Ltd., Tokyo, Japan, pp. 81-113

[16] Kawakita H, Abe M, Inoue J, Ohto K, Harada H, Inoue K. (2009). Selective gold recovery using orange waste. Sep. Sci. Technol., 44: 2797-2805.

[17] Dhakal RP, Ghimire KN, Inoue K. (2005). Adsorptive separation of heavy metals from an aquatic environment using orange waste. Hydrometallurgy, 79: 182-190. 
[18] Paudyal H, Pangeni B, Inoue K, Kawakita H, Ohto K, Harada H, Alam S. (2011). Adsorptive removal of fluoride from aqueous solution using orange waste loaded with multi-valent metal ions. J. Hazard. Mater., 192: 676-682.

[19] Paudyal H, Pangeni B, Inoue K, Matsueda M, Suzuki R, Kawakita H, Ohto K, Biswas BK, Alam S. (2012). Adsorptive behavior of fluoride ion on $\mathrm{Zr}(\mathrm{IV})$ loaded orange waste gel from aqueous solution, Sep. Sci. Technol., 47: 96-103.

[20] Paudyal H, Pangeni B, Inoue K, Kawakita H, Ohto K, Ghimire KN, Harada H, Alam S. (2013). Adsorptive removal of trace concentration of fluoride ion from water by using dried orange juice residue, Chem. Eng. J., 223: 844-853.

[21] Liao XP, Shi B. (2005). Adsorption of fluoride on zirconium(IV)-impregnated collagen fiber, Environ. Sci. Technol., 39: 4628-4632.

[22] Paudyal H, Pangeni B, Inoue K, Kawakita H, Ohto K, Ghimire KN, Alam S. (2013). Preparation of novel alginate based anion exchanger from Ulva japonica and its application for the removal of trace concentration of fluoride from water, Biores. Technol., 148, 221-227.

[23] Viswanathan N, Sundaram CS, Meenakshi S. (2009).: Sorption behavior of fluoride on carboxylated cross-linked chitosan beads, Coll. Surf. B; Bioint., 68, 48-54.

[24] Fang L, Ghimire KN, Kuriyama M, Inoue K, Makino K. (2003). Removal of fluoride using some lanthanum loaded adsorbents with different functional groups and polymer matrices, J. Chem. Technol. Biotechnol., 78: 1038-1047.

[25] Gupta VK, Ali I, Saini VK. (2007). Defluoridation of wastewaters using waste carbon slurry, Wat. Res., 41, 3307-3316: 2007.

[26] Mohan VS, Ramanaiah SV, Rajkumar B, Sharma PN. (2007). Bio-sorption of fluoride from aqueous solution onto algal spirogyra IO1 and evaluation of adsorption kinetics, Biores. Technol., 98: 1006-1011.
[27] Gao S, Cui J, Wei Z. (2009). Study on the fluoride adsorption of various apatite materials in aqueous solution, J. Fluo. Chem., 130: 1035-1041.

[28] Zhao Y, Li X, Liu L, Chen F. (2008). Fluoride removal by $\mathrm{Fe}$ (III)-loaded ligand exchange cotton cellulose adsorbent from drinking water, Carbohydr. Polym., 72: 144-150.

[29] Viswanathan N, Meenakshi S. (2010). Enriched fluoride sorption using alumina/chitosan composite, J. Hazard. Mater., 178: 226-232.

[30] Daifullah AAM, Yakout SM, Elreefy SA. (2007). Adsorption of fluoride in aqueous solution using $\mathrm{KMnO}_{4}$ modified activated carbon derived from steam pyrolysis of rice straw, $J$. Hazard. Mater., 147: 633-643.

[31] Sathish RS, Sairam S, Raja VG, Rao GN, Janardhana C. (2008). Defluoridation of water using zirconium impregnated coconut fiber carbon, Sep. Sci. Technol., 43: 3676-3694.

[32] Paudyal H, Pangeni B, Inoue K, Kawakita H, Ohto K, Alam S. (2012). Removal of fluoride from aqueous solution by using porous resin containing hydrated oxide of cerium (IV) or zirconium (IV). J. Chem. Eng. Japan, 45: 331-336.

[33] Kemer B, Ozdes D, Gundogdu A, Bulut VN, Duran C, Soylak M: Removal of fluoride ions from aqueous solution by waste mud, J. Hazard. Mater., 168, 888-894, 2009.

[34] Tor A. (2006). Removal of fluoride from an aqueous solution by using montmorillonite, Desalination, 201, 267-276.

[35] Sundaran CS, Viswanathan N, Meenakshi S. (2008). Uptake of F by nanohydroxyapatite/chitosan:- a bioinorganic composite, Biores. Technol., 99, 8226-8230.

[36] Islam M, Patel RK. (2007). Evaluation of removal efficiency of fluoride from aqueous solution using quick lime, J. Hazard. Mater., 143, 303-310. 